\title{
Research on Zoology Teaching under the Credit System Mode*
}

\author{
Ruilin Tian \\ Corresponding Author \\ College of Life Sciences and Technology \\ Inner Mongolia Normal University \\ HuHot, China 010022
}

\begin{abstract}
Zoology is an important basic course for undergraduates majoring in biology, in order to guarantee and improve the zoology teaching quality after reform of the credit system, based on the teaching practice, the article discusses and confirms that to keep the integrity of zoology knowledge system and highlight main knowledge is a precondition to guarantee the teaching quality. In order to further better the teaching quality and improve teachers' teaching level, this article makes discussions on how to adopt flexible and diverse teaching methods and how to conduct a professional thought education in time.
\end{abstract}

Keywords-zoology; knowledge system; credit system; professional thought

\section{INTRODUCTION}

Credit system is a basic educational and teaching system that is widely adopted in most universities throughout China and the world and it is a modern educational and teaching system, advocating a philosophy and spirit college education that contain strong modern elements, and what it is focused on is new concept of education and teaching[1]. With the development of the time and the rapid progress of science and technology, new knowledge and theories emerge one after another, which bring a massive increase of knowledge and diversified demands to talents by the society. More courses will be set with class hours reduced correspondingly for each course so as to adapt to the unlimited knowledge and the limited class hours. [1] The credit system teaching introduced to the undergraduate education brings an effective way to deal with the massive knowledge, limited class hours as well as the diversified demands to talents by the society.

Zoology is one of the core courses for undergraduates majoring in the life science, a basic and pilot one for special learning, and it will place a solid foundation relative to animal morphology and evolution for the subsequent biochemistry, genetics, zoonomy, cytology and evolutionary biology[2] [3] [4]. With the courses added, more optional courses and class hours concerned reduced, in order to well disseminate special basic courses and improve the teaching quality continuously, this author explores the teaching reform of zoology on the basis of teaching practice and 2017). experience in zoology in the past years.

\section{STRESS THE INTERPRETATION OF COMPLETE \\ KNOWLEDGE S YSTEM AND AVOID USING KNOWLEDGE POINTS TO REPLACE THE KNOWLEDGE SYSTEM}

Zoology is a branch of biology, a basic discipline to study the morphological structure, taxonomic status, occurrence and development regularity, which is widely involved[5] [6] [7]. Animals are diverse in variety and different in morphological structure and life habit, so there are more zoology knowledge points, large involvement and abundant information, correspondingly there are many terminologies and concepts as well. So in the course of zoology teaching, it is always said difficult to learn for students, though some problems that teachers interpret are understandable for students, yet when they review a complete content or make systematic comparison with new knowledge, they find they cannot remember what they have learned at all. Main reasons for the phenomena are that the students fail to grasp the knowledge structure of the course; as a result, they cannot completely understand the knowledge. Accordingly during teaching, the teachers should insist on the "complete knowledge", stress the knowledge from of the knowledge concerned but not just the knowledge points, so that the students may get the whole knowledge at a higher level and grasp it in all aspects.

\section{A. Grasp the Overall Knowledge Frame of Zoology and Highlight the Main Knowledge}

With the class hours reduced and less teaching time for teachers compared to that in traditional teaching, it may easily cause "some contents are reduced by some limits", and the class teaching is changed to the interpretation of some knowledge points. For students, what they need are just key points to grasp the key knowledge points which are loose in consistency but enough to pass the final exams so as to get corresponding credits and GPA. As a result, the teaching does no good to improving the teaching quality, which is far to place a solid foundation for the subsequent special learning.

Less class hours shall not be a simple reduction in the class hour, actually it requires highlighting the main lines with the whole framework guaranteed. Any course has a 
knowledge system of its own, which consists of basic concepts, research methods and achievements. Connect the numerous knowledge points to form a main line for the knowledge system of animal evolution. The zoology starts with unicellular animals, followed by multi-cellular animals successively with cell and tissue differentiations formed, based on which, all kinds of organs and systems grow gradually, so do representative animals and corresponding taxonomic category in each stage. While grasping morphological characteristics of main groups, stress morphological structure and functions, relations between adaptation and evolution, aiming to deepening the understanding of animal structure and functions, individual development and phylogeny, as well the unit of organism and environment[8]. So there always some continuity in structure and function between important animal classes, namely main lines to connect the knowledge points are the animal evolution[3] [9]. As long as we grasp the overall framework and highlight the key points, we will not be limited by narration and description and not troubled by the diverse and single terminology, as such, we could thoroughly understand and combine the form and the latter to interpret the contents of each lesson[10]. In the course of teaching, we can not only stress the key teaching points but also make the knowledge more systematic, and the students can outline and grasp the overall framework and improve the memory after fully understanding.

\section{B. Make Reasonable Use of References and Relevant Research Achievements}

At present, as for the courses set for undergraduates especially those required, special textbooks are provided and ordered by colleges. Actually the textbooks are mainly used as references, which are different from standard textbooks used in primary and middle schools. Purposes of the undergraduate education are to make students understand basic knowledge system and the latest development of a course[9], therefore, it cannot designate a book as textbook, and the textbook can be used as references only. There are many textbooks in libraries and bookstores which are used as references, which play an important role in expanding the students' knowledge and horizon during both the teaching and learning. However, we should not take the teaching process simply as an interpretation of a textbook, for any one of the textbooks cannot contain entire contents and knowledge standard for teaching[11]. Teachers must know about main contents and layout of mainstream textbooks and study the latest articles and literature reviews relative to key knowledge points, though many contents are not what the teachers study, in order to improve the quality and achieve the necessary teaching tasks, they still have to face it carefully and spend time and energy necessary. As such, can the roles of textbooks and references be fully exerted, relying on teachers' interpretation, the students may memorize relevant contents, which may do good to further understanding the connotation and extension of the zoology.

\section{FULLY EXERT THE LEADING ROLE OF TEACHERS AND STRESS METHODS TO ACQUIRE KNOWLEDGE}

Basic professional courses are generally set at grade I and grade for teaching, and what the students receive in junior and senior high schools are intensive teaching, and the learning tasks are completed under the supervision of teachers and parents. College education is not intensive and massive exercise training but quick and outlined with self study required. After being admitted to a college, the students are unfamiliar with the learning mode there, most of whom are in the lack of independent learning, especially their learning are over depending on teachers, expecting teachers to collect the teaching contents, give key points and examined scopes, having no confidence of independent learning, worse in independent learning and even feeling uncomfortable in independent learning[11]. Therefore, the basic course teaching for freshmen at the beginning has to bear the mission to change students' learning modes, the teachers shall teach students how to acquire knowledge and stress the cultivation of students' abilities of independent learning.

\section{A. Teachers Shall Improve the Teaching Level of Their Own and Well Master the Professional Cultivation Program}

As disseminators, teachers are predominant in the teaching, and their professional knowledge and teaching level are preconditions to guarantee the cultivation of talents. The teaching is a process through which the knowledge and culture that we have owned are passed to the next generations, however, it is not a simple repeat, but passes students the essence and important achievements which are refined and processed systematically within the limited class hour, with the knowledge system built and taught layer after layer, the students will acquire new knowledge continuously through the learning.

The credit system requires that teachers should guarantee the teaching quality, that is, whether the teaching level and knowledge structure can meet the talent cultivation are key factors. Teachers are main strengths for cultivating talents in colleges and main bodies of scientific research. One of the goals of scientific research in colleges to meet the discipline construction, whose result will directly affect the knowledge structure of teachers, the discipline given herein refers to knowledge. So the knowledge layout connecting the cultivation goals and course setting may well integrate teachers' research field (orientation) and teaching tasks, and the improvement of teachers' quality also guarantee the quality of talent cultivation.

Zoology teachers shall understand the cultivation program and course setting of the discipline, generally there shall be not more than 2-3 basic courses for zoology major in the cultivation program such as zoology, botany, microbiology and so on, which will place solid foundation for the coming major learning. Different majors have different cultivation goals and features, so do the major courses, therefore, the requirements for knowledge structure of basic courses differ. To master the cultivation program of 
the major and understand the internal relations of course setting will open necessary windows and provide connecting points fro the following major courses, "make full efforts to integrate all courses as a whole", and reach the requirements of knowledge structure, ability structure and quality structure as required in the cultivation program.

\section{B. To Cultivate Students' Abilities of Independent Learning Is A Task Needed to Persist and Complete}

In the era of big bang of knowledge and massive knowledge, the college teaching cannot teach students all knowledge, it is also unrealistic, therefore, getting methods to acquire knowledge becomes a necessary condition to be talented. Zoology cannot show entire contents with a limited class hour, so in the course of teaching, to cultivate independent learning is an important task. Knowledge is unlimited, especially traditional disciplines like zoology, with the time going, new species, structures and functions will be found and described continuously, and the theories and methods change day by day. Teachers cannot teach students all knowledge, therefore to teach students how to acquire knowledge is much more important than the specific interpretation of knowledge. During the teaching, according to the knowledge to learn, it needs to cultivate students' abilities of active learning and how to learn so that the limited class teaching will be converted into unlimited independent learning and abilities of permanent learning to improve the results, which play an important role in the students' development for a long time[4]. Instructed by teachers, the students may self teach some contents, able to look up relevant references, and such training is very important for students and achieves a lot. Arrange five students to form a group, each of them will take charge of pre-review, collection of data and task review in turns, every time, a member of the group will make reports with other members to make up, which will occupy about ten minutes in class, besides, the attendance can be seen as well[12]. Some may have different interpretations, which bring great help to understanding of the current research achievements. The training and requirements convert students' learning mode to "able to learn" from "learn to do", teach them how to identify from east to west, south and north, and gradually train students' habits of discovering problems, raising problems, discussing problems and solving problems[13]. Combine the independent learning and research-based teaching so as to place a solid foundation for the learning of major courses in the future.

\section{Stress Professional Thought Education}

After being admitted to college, all the students are expecting to feel the core contents of the zoology major that they have selected, this stage will be a golden one for professional thought education. Maybe the entrance education and other non-class occasion may provide professional thought education, actually main contents are introduced to them. In the opinion of the author, the efficient way is to set basic professional courses in the stage and conduct professional thought education step by step, which will be good to the students' learning in following years.
Due to the diversity of social demand for talents, employment pressure and so on, the professional thoughts of low-grade college students are unstable, most of which are in confusion. During the teaching, we should intensify the professional awareness, with the major oriented, teachers shall introduce other major courses on the basis of major courses and necessary knowledge closely related to the post demand of the major, stress the position and roles of the courses in the talent training system as well as understanding of the teaching goals. As such, it can efficiently stabilize students' professional thoughts, cultivate professional interests and guarantee the improvement of teaching effect [7].

\section{FleXible ApPlicAtion OF MUltiple Teaching TOOLS AND METHODS}

The zoology is very broad in content, including various types of animal morphology, function and evolution in different living environments. Based on the PPT courseware, multiple teaching methods are adopted to improve the teaching effect. And the combination of specimens, models, pictures and videos are used convert a lot of abstract contents or those which are hard to express by languages into contents which are intuitive and easy to understand, so as to stimulate students' interests in learning and improve classroom teaching effect. While excelling in the visual means, teachers shall pay more attention to the blackboard writing. With key words and fine structures shown on the blackboard, the students may follow the order of stroke to understand and remember, which greatly improves the teaching effect, which do good the to good writing and painting quality education.

The zoology teaching needs to borrow multiple teaching methods, according to the teaching contents, teachers shall adopt comparison method, elicitation and research teaching, etc. Animals have all kinds of species and there are large differences among species. Suppose arrange students to member characteristics of each kind of animals, it will cause too many knowledge points and difficulty to remember. Adopt the comparison method and make students understand the distinction and connection of animals in characteristics, and maser the evolution relations from animals and complicated evolution. For example, when animals evolve from single cell to multiple cells, it will produce cell differentiation, followed by tissues and organs. The formation of animal organs is in order, through comparisons, the students may really know which organs are formed from what animals initially, and the knowledge former and latter is connected. The heuristic teaching method is often used in classroom teaching, which can activate the classroom atmosphere and help teachers interact with students, which shall be well mastered.

At present, research teaching is widely recommended for the teaching reform in colleges, which plays an irreplaceable role in cultivating students' interest in discipline, improving the motivation in learning and broadening students' vision [14] [15]. The research teaching can be introduced to the zoology teaching as planned, arrange tasks as per groups and look up relevant information, collect and summarize what each student has learned and writing group reports and show 
in class [16]. For example, discuss the differentiation age of protostomia and deuterostome and the adaptive evolution process of protostomia among invertebrates, arrange students to look up data and grasp the differentiation of early metazoan and further understand the evolution process of invertebrate from aquatic to land. Echinoderms and chordates both belong to deuterostome, which also experienced the evolution from aquatic to land, it, together with the evolution of the protostomia formed the largest parallel evolution in the animal field [17]. After being introduced to the contents, the research teaching not only cultivates a spirit of exploration while disseminating knowledge, but also achieve the goals of training union, cooperation and devotion, and scientific literacy, thinking and rigorous style are integrated to the teaching.

\section{REFERENCES}

[1] Bie Dunrong. Study on the Educational Principles and Application Requirement of the Academic Credit System. 2013, 3: 6-15. (In Chinese)

[2] Dai Xin, Yang Feng-Ping, Li Shi-Pimg, Yin Bao-Fa, Wei Wan-Hong. Discussion on teaching reform of zoology. China Education Innovation Herald, 2013， 13: 107-108. (Chinese)

[3] Su Shi-Ping, Fang Fu-Gui, Ding Shu-Quan. The exploration of general zoology teaching in the small courses. Journal of Biology, 2011, 28 (5): 105-107. (In Chinese)

[4] Zhang Lu-Qiang. A primary discussion on zoology course teaching. Journal of Biology, 2004, 21 (4): 42-44. (In Chinese)

[5] Liu Ling-Yun, Zheng Guang-Mei. General Zoology (Forth Edition). Higher Education Press, Bei Jing, 2009: 1-12. ( Chinese)

[6] Hou Lin, Wu Xiao-Bing. Zoology. Science Press,Bei Jing, 2007: 1448. ( Chinese)

[7] Xu Cong-Ren, Cheng Hong. Animal Biology ( Second Edition) . Higher Education Press, Bei Jing, 2008: 35-159.

[8] Su Jun-Hu, Wang Jing. Discussion on teaching methods of the zoology course. Higher Education Forum，2013， 8: 74-76.

[9] Wen Long-Ying, Fu Yi-Qiang, Nie Li, Ren Wei-Yi, Cao Cheng-Quan. Discussion of zoology's teaching based on the evolution as a main line. Modern Agricultural Science and Technology, 2013, 10: 330331. (In Chinese)

[10] Zhang Zhi-qiang. Experience and improvement of teaching method of zoological course in higher agricultural university. Journal of Biology, 2014, 31 (4): 110-112. (In Chinese)

[11] Xing Wan-Jin, Morigen, Su Hui-Min. Primary discussion on reformation of genetics teaching. Journal of Biology, 2012, 29 (3): 105-107. (In Chinese)

[12] Li An-Ning, Dong Wu-Zi, Shi Huai-Ping, Wu Li-Juan. Innovation on zoology curriculum and teaching. Acta Ecologiae Animalis Domastici, 2014, 35 (8): 94-96. (In Chinese)

[13] Luo Lan, Wu Yan-Rui, Fan Biao, Fan Zhi-Xiang, Chen YuanXiao. The teaching practice of medical cell biology under the background of the credit system reform. Journal of Yunnan University (S1) , 2014，36(S1):154-156. (In Chinese)

[14] Han Li-Min. Application of research teaching strategy based on the cultivation of innovative talents in the course of gene engineering. Journal of Biology, 2015, 32 (4): 110-113. (In Chinese)

[15] Yu Wei-Yan, Chen Quan-Zhan, Li Zhao-Hui, Song Dong-Jie, Sun Hui, Jin Li-Xue, Li Yu-Xiu, Wang Hui. Probe of the putting out selflearning in university on zoology teaching. Journal of Biology, 2009, 26(5): 83-85. (In Chinese)

[16] Xing Wan-Jin, Morigen, Su Hui-Min. An exploration for researchoriented teaching model in biology teaching. Hereditas (Beijing), 2014， 36 (7): 732-738. (In Chinese)
[17] Shi Lei. Teaching zoology from the integrated biological point of view- a case of Protosome and Deuterostome. Biology Teaching in University ( Electronic Edition)，2013， 3 (3): 28-31. (In Chinese) 